\title{
O CONTADOR PÚBLICO NAS PREFEITURAS MUNICIPAIS: ESTUDO EXPLORATÓRIO NA REGIÃO METROPOLITANA DA SERRA GAÚCHA
}

\author{
THE PUBLIC ACCOUNTANT IN MUNICIPAL PREFECTURES: EXPLORATORY \\ STUDY IN THE METROPOLITAN REGION OF THE SERRA GAÚCHA \\ Diego Luís Bertollo \\ Andrea Simoni Kiekow \\ Rodrigo Triaca \\ Andre Luiz Marchalek \\ Marta Elisete Ventura Motta \\ Maria Emília Camargo
}

RESUMO: Diante das transformações tecnológicas nas organizações públicas, o profissional contábil surge como o principal agente responsável pelo tratamento e disseminação das informações contábeis e gerenciais. Num contexto de diversificação de atividades, uma das principais tarefas do Contador é produzir e gerenciar informações úteis aos usuários da Contabilidade para a tomada de decisões. Assim, esta pesquisa teve por objetivo identificar o perfil dos contadores públicos nas prefeituras municipais da região metropolitana da serra gaúcha em relação aos interesses de especialização nas áreas de atuação e nos setores que trabalham dentro do ambiente público e a postura destes perante a sociedade. Esta pesquisa caracterizou-se em sua abordagem como quantitativa, e quanto aos objetivos como descritiva, sendo que a técnica utilizada foi a aplicação de um questionário indutivo para os contadores públicos da região metropolitana da serra gaúcha buscando coletar informações para a elaboração desta pesquisa. Como principais resultados, tem-se que $68 \%$ dos entrevistados possuem curso de especialização, em relação ao domínio de informática, $60 \%$ possuem nível avançado e $92 \%$ não tem domínio de língua estrangeira. Para futuros estudos sugere-se aplicação de questionário para todos os contadores públicos do Estado do Rio Grande do Sul, a fim de conseguir identificar os perfis destes profissionais.

palavras-chave: Contabilidade Pública. Profissional Contador. Lei de Responsabilidade Fiscal.

ABstract: On technological transformations in public organizations, the professional accountant is the principal agent responsible for processing and dissemination of information and managerial accounting. In the context of diversification of activities, one of the main tasks of the Accountant is to produce and manage useful information to users of accounting for decision-making. Thus, this research aimed to identify the profile of public accountants in the municipal administrations of the metropolitan region of the serra gaúcha in relation to the interests of specialization in areas and in sectors which work within the environment public and the posture of these towards society. This research was characterized in your approach as quantitative, and how the goals as descriptive, the technique used was the application of a questionnaire for public counters inductive of the metropolitan region of the serra gaúcha seeking gather information for the preparation of this research. Main results, has that $68 \%$ of respondents have specialization course, computer domain, 
$60 \%$ have advanced level and $92 \%$ do not have mastery of a foreign language. For future studies, we suggest application of questionnaire to all public counters of the State of Rio Grande do Sul, in order to be able to identify the profiles of these professionals.

KEYwORDs: Public Accounting. Professional Accountant. Fiscal responsibility law.

\section{INTRODUÇÃO}

A Contabilidade é uma das ciências mais antigas, pois sempre esteve presente na vida do homem, que, ainda nos primórdios, buscou diversas formas de contar e registrar seu patrimônio, recebimentos e pagamentos. De acordo com Iudícibus (2009), a Contabilidade surgiu com a necessidade de registros dos comércios, o homem primitivo ao inventariar o número de instrumentos de caça e pesca disponível e contar seus rebanhos já estava praticando uma forma inicial de Contabilidade.

Na administração pública a contabilidade está presente e desempenha papel relevante, pois é através dela que se pode oferecer ao administrador as informações necessárias para que este possa tomar decisões durante sua gestão frente ao Poder Executivo e desta forma obter êxito. As administrações públicas após a Lei de Responsabilidade Fiscal - LRF, entraram na era do planejamento para que suas ações nos gastos públicos atendam os anseios da população.

De acordo com Lima (2008) a contabilidade publica é uma especialização da ciência contábil que aplica processo gerador de informações os dossiês, princípios e normas contábeis na gestão patrimonial de uma entidade pública oferendo a sociedades informações amplas e acessíveis sobre a gestão da máquina pública.

A área contábil é promissora e vasta possuindo diversos ramos para atuação, segundo Marion (2009), o bacharel em Ciências Contábeis pode atuar como auditor, perito, contador de custos, analista financeiro, consultor, professor, pesquisador, assumir cargos administrativos, cargos públicos, entre outros, em função do grande leque de oportunidades a área para especialização torna-se para alguns uma difícil escolha.

De acordo com Silva (2003), o profissional contábil precisa ser visto como um comunicador de informações essenciais à tomada de decisões, pois a habilidade em avaliar fatos passados, perceber o presente e predizer eventos futuros pode ser compreendido como fator preponderante ao sucesso empresarial. Pode ser considerado como um agente de mudanças, e como tal esse profissional deve mostrar suas diversas habilidades, tornando-se seu profundo conhecedor, podendo desta forma atuar em sua continuidade e crescimento (SILVA, 2011).

O presente artigo busca contribuir para a conscientização profissional do contador bem como de outros profissionais relacionados à área, no exercício das atividades de controle público interno e externo. 
Explicita a necessidade do contabilista de balizar sua postura profissional, de acordo com anseios da sociedade, enquanto ator integrante do sistema de controle. $\mathrm{O}$ contador deve aproveitar o grande momento de abertura da gestão pública além do exercício do controle social sustentado pela accountability (prestação de contas), e procurar ocupar espaço central na prestação de contas sociais, sem abrir mão dos princípios da moralidade e legalidade, fazendo chegar à sociedade as informações imprescindíveis ao exercício da cidadania.

Assim, o objetivo da pesquisa consiste em identificar o perfil dos contadores públicos na região metropolitana da serra gaúcha e suas áreas de especialização e enquadramento dentro do setor de contas públicas.

Este estudo está estruturado da seguinte forma: a segunda seção aborda brevemente o referencial teórico da profissão contábil, contabilidade pública, normas brasileiras de contabilidade aplicadas ao setor público, áreas de atuação do profissional contábil e perfil do mesmo. Em seguida foi explicitado os procedimentos metodológicos para apresentar na quarta seção a análise dos resultados e na quinta seção as considerações finais

\section{REFERENCIAL TEÓRICO}

\subsection{PROFISSÃO CONTÁBIL}

Segundo ludícibus (2007), em alguns segmentos da economia do país, principalmente na pequena empresa, a função do contador foi distorcida, estando voltada quase que exclusivamente para satisfazer às exigências do fisco.Com o avanço das tecnologias, surge uma demanda na diversificação e agilização no processamento de atividades, fazendo com que a tarefa básica do Contador seja produzir e/ou gerenciar informações úteis aos usuários da Contabilidade para a tomada de decisões (IUdicíbus, 2007). Poder avaliar os fatos passados, perceber os presentes e ter uma previsão dos futuros, coloca o profissional contábil também como uma grande ferramenta para o sucesso das empresas (SILVA, 2003).

A implementação das Leis nº 11.638, de 28 de dezembro de 2007 e $\mathrm{n}^{\mathrm{o}}$ 11.941, de 2009, que alteram e revogam dispositivos da Lei $\mathrm{n}^{\mathrm{0}}$ 6.404, de 1976, a qual tem como objetivo atualizar as regras contábeis, observando as práticas internacionais, criou um desafio para o profissional contábil, mas, ao mesmo tempo, ampliou o leque de oportunidades onde este profissional poderá atuar, justificando as tendências internacionais de um mercado cada vez mais aberto e comum a todos.

O profissional da área contábil deve exercer com ética as atribuições e prerrogativas que lhes são prescritas através do Código de Ética editado pelo CFC, assim como, desenvolver uma consciência voltada a atender as responsabilidades para com a sociedade enquanto indivíduo. Somente com condutas pautadas na responsabilidade ética, moral e social é que o profissional poderá se desenvolver, que é o responsável 
pela alimentação das informações que os usuários tomam como base e parâmetro para tomarem suas decisões de investimento ou gestão (KOUNROUZAN, 2002).

Em consonância a isso, Iudícibus (2007) diz que o profissional contábil torna-se um instrumento importante para o sucesso e continuidade de uma organização, pois fornece informações necessárias que possibilita aos gestores acompanhar a execução dos objetivos estabelecidos, produzindo ou gerenciando informações aos usuários a fim de auxilia na tomada de decisão.

\subsection{CONTABILIDADE PÚBLICA}

O objetivo principal da contabilidade é fornecer informação econômica relevante para que cada usuário possa tomar suas decisões e realizar seus julgamentos com segurança (SLOMSKI, 2003). Além disso é uma ciência que permite por meio de técnicas, registrar todos os atos e fatos relevantes, controlando o patrimônio e oferecendo subsídios para uma adequada tomada de decisão (LIMA, 2000).

A Contabilidade Pública é o ramo da Contabilidade, que tem por objetivo aplicar os conceitos, Princípios e Normas Contábeis na gestão orçamentária, financeira e patrimonial dos Órgãos e Entidades da Administração Pública, oferecendo à sociedade, de maneira transparente e acessível, o conhecimento amplo sobre a gestão da coisa pública (LIMA, 2003). Para Glauber (2005) registra a previsão da receita e a fixação da despesa estabelecidas no orçamento público aprovado para o exercício, escritura a execução orçamentária, faz a comparação entre a previsão e a realização das receitas e despesas, revela as variações patrimoniais, demonstra o valor do patrimônio e controla: as operações de crédito; a dívida ativa; os créditos; e as obrigações.

Além disso Lima (2012), descreve a contabilidade pública como o conhecimento especializado da Ciência Contábil que aplica no processo gerador de informações, os conceitos, princípios e normas contábeis na gestão patrimonial de uma entidade governamental, de sorte a oferecer à sociedade informações amplas e acessíveis sobre a gestão da coisa pública. De acordo com Mello (2008), a contabilidade pública exerce a função de prever, escriturar, controlar, analisar e interpretar os atos e fatos da gestão pública.

A Lei $n^{0}$ 4.320/64 institui as normas a serem seguidas pelas entidades, sendo aplicada na elaboração do orçamento público e a administração pública, padroniza a Contabilidade Pública no Brasil, para todas as esferas do governo: União, Estados, Municípios, Distrito Federal, empresas estatais e autarquias (NASCIMENTO, 2008).

A Lei de Responsabilidade Fiscal (LRF), LC 101, trouxe consigo os importantes pontos de controle para os gestores públicos: (i) planejamento voltado a resultados; (ii) limitação de gastos e do endividamento; (iii) limitação nos gastos com pessoal; (iv) regras rígidas para a renúncia de receita; (v) preservação do patrimônio público; (vi) transparência das contas públicas (AZEVEDO, 2013). 
A LRF não substitui nem revoga a Lei $\mathrm{n}^{\mathrm{0}}$ 4.320/64, que normatiza as finanças públicas no País há quase 40 anos. Embora a Constituição Federal tenha determinado a edição de uma nova lei complementar em substituição à Lei 4.320, não é possível prever até quando o Congresso Nacional concluirá os seus trabalhos em relação ao projeto já existente (NASCIMENTO, 1998).

\subsubsection{LEI DE RESPONSABILIDADE FISCAL}

A Lei de Responsabilidade Fiscal - Lei Complementar $n{ }^{\circ}$ 101, de 4 de maio de 2000, visa regulamentar a Constituição Federal, na parte da Tributação e do Orçamento (Título VI), cujo Capítulo II estabelece as normas gerais de finanças públicas a serem observadas pelos três níveis de governo: Federal, Estadual e Municipal (NAscimento, 1988). Nesse sentido, Reis (2001) acrescenta que a LRF visa disciplinar o comportamento do gestor público, à luz dos princípios éticos ligados à Administração, como planejamento, equilíbrio financeiro, economicidade, produtividade, transparência, controle e responsabilidade.

Tendo como principal foco a gestão fiscal incluindo aspectos relativos ao planejamento, ao orçamento, à programação financeira e ao fluxo de caixa. Do mesmo modo, Sacramento (2005), afirma que esta lei se estende à União, aos Estados, ao Distrito Federal e aos Municípios, à administração direta e indireta, e em cada uma dessas esferas de governo, aos poderes Executivo, Legislativo e Judiciário, bem como ao Ministério Público, a LRF está apoiada em quatro eixos, quais sejam planejamento, transparência, controle e responsabilização.

Expresso literalmente no texto da LRF, o planejamento figura, por assim dizer, como o ponto de partida para o seu entendimento. Contando com vinte e oito artigos que tratam direta ou indiretamente desse tema, a LRF cria novas informações, metas, limites e condições para a renúncia de receita, para a geração de despesas, inclusive com pessoal e de seguridade, para assunção de dívidas, para a realização de operações de crédito, incluindo antecipação de receita orçamentária, e para a concessão de garantias, o que evidencia que a disciplina fiscal somente poderá ser alcançada com o adequado planejamento das ações de governo e da execução orçamentária (vigNOLI, 2002).

No que se refere ao planejamento do gasto público, tem-se regulamentado por esta lei, os três instrumentos previstos já na Constituição e agora revigorados pela nova lei: o Plano Plurianual - PPA, a Lei de Diretrizes Orçamentárias - LDO e a Lei Orçamentária Anual - LOA. Por sua vez a transparência será alcançada através do conhecimento e da participação da sociedade, assim como na ampla publicidade que deve cercar todos os atos e fatos ligados à arrecadação de receitas e à realização de despesas pelo poder público (NASCIMENTO, 1998).

Diversos mecanismos estão sendo instituídos pela LRF para fins de atendimento a práticas de transparência, dentre elas: a participação popular na discussão e elaboração dos planos e orçamentos já referidos (artigo 48, parágrafo único); a disponibilidade das contas dos admi- 
nistradores, durante todo o exercício, para consulta e apreciação pelos cidadãos e instituições da sociedade; a emissão de relatórios periódicos de gestão fiscal e de execução orçamentária, igualmente de acesso público e ampla divulgação.

O controle das contas públicas com o advento da LRF foi bastante aprimorado e é uma consequência natural da transparência e da qualidade das informações. Deve ser exercido interna e externamente, cabendo ao Poder Legislativo, com o auxílio dos Tribunais de Contas, e a população verificar se as metas previstas estão sendo cumpridas, pelo exame dos relatórios e dos anexos incorporados ao planejamento (ZIVIANI, 2004).

Por conseguinte, a responsabilização constitui num aspecto contundente da LRF e deverá ocorrer sempre que houver descumprimento das regras nela estabelecidas. Assim é que para assegurar a efetividade da LRF, foram criadas as sanções institucionais (aquelas que recaem sobre o ente público) e pessoais (que recaem sobre o agente que der causa ou infração administrativa) e através da Lei 10.028/00, de 19.10.00, denominada Lei de Crimes de Responsabilidade Fiscal, alterações foram processadas no Código Penal Brasileiro para garantir a responsabilização dos seus transgressores (SACRAMENTO, 2005).

\subsubsection{PLANO PLURIANUAL (PPA)}

O Plano Plurianual (PPA) exerce a função de estabelecer as diretrizes, objetivos e metas da administração para as despesas de capital e outras delas decorrentes (NASCIMENTO, 1998). Sua vigência é de quatro exercícios financeiros, devendo seu projeto ser enviado para aprovação da Casa Legislativa, nos termos da Lei Orgânica Municipal, sempre no primeiro ano de mandato do chefe do poder executivo. A coordenação da elaboração do projeto da Lei do Plano Plurianual cabe ao Ministério do Planejamento, Orçamento e Gestão, por intermédio da Secretaria de Planejamento e Investimentos Estratégicos e envolve a ativa participação de todos os órgãos da Administração Direta e Indireta do governo federal. O PPA foi concebido para desempenhar papel estruturador, organizador e compatibilizador de toda a ação governamental (CALMON, 2002).

Para Lunelli (2002), com a adoção deste plano, tornou-se obrigatório o Governo planejar todas as suas ações e também seu orçamento de modo a não ferir as diretrizes nele contidas, somente devendo efetuar investimentos em programas estratégicos previstos na redação do PPA para o período vigente. Conforme a Constituição, também é sugerido que a iniciativa privada volte suas ações de desenvolvimento para as áreas abordadas pelo plano vigente.

\subsubsection{LEI DE DIRETRIZES ORÇAMENTÁRIAS (LDO)}

No Brasil, a Lei de Diretrizes Orçamentárias (LDO) tem como a principal finalidade orientar a elaboração dos orçamentos fiscal e da seguridade social e de investimento do Poder Público, incluindo 
os poderes Executivo, Legislativo, Judiciário e as empresas públicas e autarquias. Busca sintonizar a Lei Orçamentária Anual com as diretrizes, objetivos e metas da administração pública, estabelecidas no Plano Plurianual (LUNELLI, 2002).

Da mesma forma, Kohama (2003) comenta que a LDO tem a finalidade de nortear a elaboração dos orçamentos anuais, compreendidos aqui o orçamento fiscal, o orçamento de investimentos das empresas e os orçamentos da seguridade social, de forma a adequá-las às diretrizes, objetivos e metas da administração pública, estabelecidas no plano plurianual.

\subsubsection{LEI ORÇAMENTÁRIA ANUAL (LOA)}

De acordo com Gontijo (2004), a lei orçamentária da União estima receitas e fixa as despesas para um exercício financeiro. De um lado, permite avaliar as fontes de recursos públicos no universo dos contribuintes e, de outro, quem são os beneficiários desses recursos. Esta lei é o orçamento propriamente dito, que Carvalho (2007) conceitua como sendo um processo contínuo, dinâmico e flexível, que traduz em termos financeiros para o período de um ano, os planos e programas de governo, em consonância com a LDO, PPA e a LRF.

Da mesma forma Nascimento (1998) comenta que a Lei Orçamentária Anual, prevista no artigo 165, parágrafo $5^{\circ}$ da Constituição Federal, é o mais importante instrumento de gerenciamento orçamentário e financeiro da Administração Pública, cuja principal finalidade é administrar o equilíbrio entre receitas e despesas públicas. Conforme o artigo 35 do Ato das Disposições Constitucionais Transitórias (ADCT), o projeto de lei orçamentária da União será encaminhado ao Legislativo até quatro meses antes do encerramento do exercício financeiro (final de agosto) e devolvido para a sanção até o encerramento da sessão legislativa (até meados de dezembro). Estes prazos, em geral, também são observados pelos Estados e Municípios.

\subsection{NORMAS BRASILEIRAS DE CONTABILIDADE APLICADA AO SETOR PÚBLICO}

As Normas Brasileiras de Contabilidade Aplicada ao Setor Público (NBCASP) foram criadas para auxiliar os contadores a cumprir suas tarefas. Têm o objetivo de uniformizar os entendimentos e interpretações na contabilidade, bem como estabelecer regras ao exercício profissional. A Resolução CFC nº 751/93 dispõe sobre as Normas Brasileiras de Contabilidade, quando estabelece regras de conduta profissional e procedimentos técnicos a serem observados quando da realização dos procedimentos, em consonância aos princípios fundamentais de contabilidade.

No ano de 2008 foi publicada a Portaria do Ministério da Fazenda n. 184, que dispõe sobre as diretrizes a serem observadas no setor público quanto aos procedimentos, práticas, elaboração e divulgação das 
demonstrações contábeis, de forma a torná-los convergentes com as Normas Internacionais de Contabilidade Aplicadas ao Setor Público (IPSASB)

\section{4 ÁREAS DE ATUAÇÃO DO PROFISSIONAL DE CONTABILIDADE EM ÓRGÃO PÚBLICO}

O profissional contábil em órgão público, pode desenvolver atividades como contador público, como auditor e controle interno (MARION, 1999). Além disso poderá gerenciar as finanças de órgãos públicos nas esferas federal, estadual e municipal, bem como também poderá exercer atividades de assessoria e planejamento. Destaca ainda que o contador passou a ser figura importante e essencial, como auxiliar de prefeitos e governadores depois da edição da lei de responsabilidade fiscal.

De acordo com Parada (2014), logística é relativo ao cálculo; denominação dada pelos gregos à parte da aritmética e da álgebra concernente às quatro operações. Parte da arte da guerra que trata do planejamento e da realização de: projeto e desenvolvimento, obtenção, armazenamento, transporte, distribuição, reparação, manutenção e evacuação de material (para fins operativos ou administrativos); recrutamento, incorporação, instrução e adestramento, designação, transporte, bem-estar, evacuação, hospitalização e desligamento de pessoal; aquisição ou construção, reparação, manutenção e operação de instalações e acessórios destinados a ajudar o desempenho de qualquer função militar; contrato ou prestação de serviços.

Poderá ainda executar atividades de logística, inclusive ocupando o cargo de intendente: é a pessoa que dirige ou administra alguma coisa; oficial integrante de um quadro ou categoria especial, ao qual incumbe a execução dos serviços financeiros e de abastecimento das organizações militares (MARION,1999).

\subsection{PERFIL DO PROFISSIONAL CONTÁBIL}

Nos últimos anos, o perfil do profissional de contabilidade vem se modificando e assim, até mesmo o conceito de emprego passa por uma profunda e irreversível transformação, que traz consigo novos padrões comportamentais de qualificação e de desempenho (sILva, 2011). No Brasil, a realidade não é tão positiva, porém, está mudando muito rapidamente e com a vinda de empresas estrangeiras que trouxe e ainda trará muitas oportunidades aos profissionais da Contabilidade (MARION, 2001).

De acordo com Silva (2003), o profissional contábil precisa ser visto como um comunicador de informações essenciais à tomada de decisões, pois a habilidade em avaliar fatos passados, perceber o presente e predizer eventos futuros pode ser compreendido como fator preponderante ao sucesso empresarial. Pode ser considerado como um agente de mudanças, e como tal esse profissional deve mostrar suas 
diversas habilidades, tornando-se seu profundo conhecedor, podendo desta forma atuar em sua continuidade e crescimento (sILVA, 2011).

Assim, faz-se necessário que o profissional contábil desenvolva estudos para conhecer as necessidades dos usuários da informação contábil e que as assimile, pois só assim poderá alcançar qualidade em seus serviços (PEREIRA, 2000). Dessa forma faz-se necessário para o profissional dispor um perfil para trabalho em equipe, liderança, motivação, identificar limites, problemas e soluções. Possuir um espírito inovador, com criatividade, flexibilidade e adaptação às mudanças. "[...] não basta, concluir o curso superior em Ciências Contábeis para garantir uma atuação profissional bem sucedida." (souzA, 2008).

E ainda destaca Oliveira (2008) que o mercado de trabalho está bem receptivo para os contadores, cabe a cada um deles procurar sua vaga através de um diferencial, ou seja, contador precisa estar sempre bem informado sobre as constantes mudanças e inovações, para que ele possa contribuir para a competitividade da empresa para a qual trabalha.

\section{PROCEDIMENTOS METODOLÓGICOS}

Em relação a abordagem do problema esta pesquisa foi caracterizada como quantitativa, objetivando identificar fatos ocorridos e analisando seus procedimentos. Para Beuren (2006) na pesquisa qualitativa, é possível realizar uma análise mais profunda do problema estudado. Já a pesquisa quantitativa traduz os resultados em indicadores numéricos. Quanto aos objetivos, esta pesquisa é classificada como descritiva, uma vez que segundo Gil (2008), descreve as características de determinadas populações ou fenômenos. A técnica utilizada foi a aplicação de um questionário. Assim, procura identificar o perfil do profissional contábil frente as atuais necessidades do mercado, no que se refere a contabilidade pública.

Este estudo limita-se a análise da atuação do profissional na área contábil, no ambiente das Prefeituras Municipais. A unidade de estudo da pesquisa contemplou as treze (13) prefeituras dos municípios, que abrangem a região metropolitana da Serra Gaúcha e foram entrevistados vinte e cinco contadores destas prefeituras.

O método utilizado para a realização desta pesquisa foi um questionário, que de acordo com Gil (2006), é uma investigação composta por um número de questões apresentadas por escrito as pessoas, com o objetivo de conhecer opiniões, crenças, sentimentos, interesses, expectativas e situações vivenciadas. Foram propostas um total de dezenove questões fechadas, visando verificar qual é o papel do contador perante a contabilidade pública abordando gênero, tempo de atuação, estrutura de pessoa no setor de atuação, posição na estrutura hierárquica, motivações da escolha da profissão, atividades executadas, especializações e habilidades técnicas e satisfação em relação à remuneração e conhecimentos de informática dos entrevistados. 
Após a coleta dos dados foi realizada a análise e interpretação dos dados, que conforme Gil (2006 p.125) consiste em estabelecer a ligação entre os resultados obtidos com outros já conhecidos, quer sejam derivados de teorias, quer sejam de estudos realizados anteriormente. Esta análise dos dados foi feita de forma descritiva a fim de apresentar os dados relativo ao perfil do profissional contábil na atualidade.

\section{APRESENTAÇÃO E ANÁLISE dOS RESULTADOS}

Os contadores públicos participaram voluntariamente da pesquisa, respondendo a diversas perguntas que possibilitaram a construção do perfil do contador público da região metropolitana da Serra Gaúcha. Foram pesquisados todos os contadores públicos da região metropolitana da Serra Gaúcha, onde totalizam treze (13) municípios, correspondendo ao número de vinte e cinco (25) contadores pesquisados.

A primeira questão apresentada aos profissionais buscou identificar qual seu gênero, entre os contadores, a análise feita dos dados indica que quatorze (14) dos vinte e cinco (25) entrevistados são homens e onze (1I) são mulheres. Este resultado corrobora com os resultados obtidos pelo Conselho Federal de Contabilidade (2013), que contabiliza que os homens são a maioria com 66,1\%. Porém, vai de encontro a pesquisa realizada por Azevedo (2010), onde $56 \%$ dos entrevistados são do gênero feminino.

Com relação ao tempo de atuação na contabilidade verifica-se que nove (9) representando o percentual de $36 \%$ tem de um (1) a cinco (5) anos na profissão e o mesmo número foi verificado quando os entrevistados estão com mais de dez (10) anos na profissão, demonstrando que há um certo nível de experiência nesta área. Este resultado reforça os obtidos pelo Conselho Federal de Contabilidade (2013), em que 75\% dos entrevistados possuem mais de dez (10) anos como contador.

Em relação ao perfil dos contadores com relação a sua posição na estrutura, que a supervisão/coordenação representa $32 \%$ entre as posições mais assumidas pelo contador público, as áreas de diretoria e analistas aparecem com $28 \%$ e $24 \%$ respectivamente.

Com relação a escolha da profissão, foi identificado que a maioria dos entrevistados escolheu mais de um motivo para justificar a escolha da profissão. A realização profissional e as oportunidades foram destaque nas respostas, com $24 \%$ em seguida aparece à experiência com $22 \%$ e ainda a percepção de que a contabilidade pública seria uma boa opção no mercado de trabalho (19\%). O conhecimento profissional foi elencado como principal motivo por $35 \%$ dos entrevistados e a estabilidade profissional aparece em segundo lugar com 31\%. Neste sentido, percebe-se que a preocupação com a garantia de emprego advinda da carreira pública é significante.

A respeito de informações referentes às atividades executadas pelos contadores os resultados foram: são responsáveis por várias operações bem como a elaboração de prestação de contas ao Tribuna de 
Contas do Estado (TCE), Secretaria do Tesouro Nacional (STN), Sistema de Informação sobre Orçamento Público em Saúde (SIOPS) e O Sistema de Informações sobre Orçamentos Públicos em Educação (SIOPE), com $19 \%$, seguido pela análise de prestação de contas da entidade $(17 \%)$ e ainda, seguidos por estes, mas não menos importantes são responsáveis pela elaboração do PPA, LDO e LOA e ainda, o dever de elaborar e analisar os resultados da Lei 4.320/64 e da LRF.

Quanto a estrutura de pessoal no setor, constatou-se que $68 \%$, das prefeituras possuem equipes para realizar as atividades. Esta maioria esta diretamente ligada ao tamanho das cidades, quanto maior a cidade maior será a quantidade de pessoal que trabalha no setor de contabilidade pública. Os cargos nos quais os contadores desempenham melhor as funções, de acordo com $52 \%$ dos questionados, apontou como sendo de consultoria. O contador pode ser uma espécie de consultor para todas as horas, auxiliando no fechamento de um novo negócio até mesmo para interpretar para o empreendedor a legislação e explicando quais são os benefícios reais de práticas, como a opção pela participação nos lucros.

A especialização também aparece sendo que $43 \%$ dos entrevistados realizam leituras em periódicos da área e $21 \%$ fazem uma educação continuada particular. Percebe-se que o avanço tecnológico e o crescimento da informação, sem limite, vêm apresentando desafios para a ciência contábil que, inevitavelmente, levarão a um redirecionamento no papel desempenhado pelos profissionais ligados a essa área. Assim o mercado atual requer modernidade, criatividade, novas tecnologias, novos conhecimentos e mudanças urgentes na visão através dos paradigmas, impondo, com isso, um desafio: o de continuar competindo.

Cursos que abordavam o tema sobre Contabilidade Pública foram os mais citados, com $49 \%$, corroborando assim com o resultado Iudícibus (1990) diz que, "para seu benefício profissional e como cidadão, o Contador deve manter-se atualizado não apenas com as novidades de sua profissão, mas de forma mais ampla, interessar-se pelos assuntos econômicos, sociais e políticos que tanto influem no cenário em que se desenrola a profissão". De acordo com Júnior e Meirelles (2009) a classe contábil espera que através da harmonização das normas de Contabilidade se alcance maior confiabilidade e transparência diante dos seus diversos usuários, a partir de informações contábeis mais seguras. Com relação a questão relacionada ao processo de convergência para a NBCASP e IPSAS, percebeu-se que o processo ainda não esta concluído, e ainda, como nos indica, $56 \%$ dos contadores públicos esclareceram que ele não será concluído até o final de 2015.

No que diz respeito ao desenvolvimento de habilidades do contador público, a questão da pesquisa sobre cursos de desenvolvimento de habilidades, os resultados apresentaram que 35\% dos entrevistados já realizaram algum tipo de curso sobre habilidade técnica, porém, 20\% nunca realizou nenhum tipo de curso. 
Complementando os resultados, o AICPA após pesquisas evidenciou como resultado, a elaboração de uma estrutura para criar habilidades técnicas, que permitirão o fortalecimento e melhor capacitação da profissão contábil em 2011. Os três componentes dessa estrutura são:

i) definição das competências necessárias para exercer a profissão;

ii) melhorar as práticas de ensino;

iii) meios para avaliar continuamente os currículos de ensino.

Os questionados responderam a questão sobre a utilização do idioma estrangeiro na profissão, dos quais $92 \%$, não utilizam idioma estrangeiro. Porém, este resultado não quer dizer que os entrevistados tenham ou não a especialização em alguma língua estrangeira. Sabe-se que o mercado precisa de pessoas que dominem idiomas, principalmente inglês e espanhol, e que acompanhem normas internacionais da contabilidade (PASCOALOTO, 2010).

A questão aplicada sobre a satisfação da remuneração ser justa, ou se deveria ser mais alta ou deveria ser mais baixa, foram identificados que para $52 \%$ dos respondentes, a remuneração paga hoje para os contadores públicos é vista como justa para a maioria dos entrevistados. Pode-se entender então, que este profissional está valorizado e incentivado perante a sua entidade e que possui afinidade e sempre procura participar de eventos e cursos sobre sua área de atuação.

Na última questão do questionário, buscou-se analisar o nível de conhecimento em informática dos contadores públicos entrevistados, na qual identificou-se que $60 \%$ dos pesquisados encontram-se no nível avançado.

\section{CONSIDERAÇÕES FINAIS}

Com as transformações tecnológicas nas organizações públicas, o profissional contábil surge como o principal agente responsável pelo tratamento e disseminação das informações contábeis e gerenciais. Num contexto de diversificação de atividades, uma das principais tarefas do Contador é produzir e gerenciar informações úteis aos usuários da Contabilidade para a tomada de decisões. De acordo com Iudicíbius (2007) a diversificação e agilização no processamento de atividades, fazendo com que a tarefa básica do Contador seja produzir e/ou gerenciar informações úteis aos usuários da Contabilidade para a tomada de decisões.

Percebe-se então o crescimento da informação com este avanço tecnológico, apresentando assim desafios para a ciência contábil que, inevitavelmente, levará a um redirecionamento no papel desempenhado pelos profissionais ligados a essa área. Assim o mercado atual requer modernidade, criatividade, novas tecnologias, novos conhecimentos e mudanças urgentes na visão através dos paradigmas, impondo, com isso, um desafio: o de continuar competindo. 
Nesse sentido, o profissional contador, conhecendo sua importância e responsabilidades perante os órgãos governamentais e a sociedade, deverá zelar por esta, exercer sua prática com ética, que ganhou força com a regulamentação do Código de Ética, no qual prevê os direitos, deveres e penalidades da profissão.

Ao ingressar na carreira pública torna-se necessário efetuar uma prova em concursos públicos, sabendo que o contador deve estar ciente da responsabilidade que ele necessita para poder trabalhar num órgão municipal. Para que ocorra um bom gerenciamento de empresas e no ambiente público, o contador tornou-se indispensável, pois auxilia de forma competente seus gestores. A valorização profissional, o incentivo da gestão pública e identificação com a área, são argumentos importantes para que o profissional se sinta realizado, motivado e satisfeito para contribuir em uma melhor administração de seu município.

O questionário aplicado aos profissionais do setor de contabilidade da região metropolitana da serra gaúcha identificou como principais resultados foram que $56 \%$ dos entrevistados correspondem ao sexo masculino, sendo que $8 \%$ não tem domínio de língua estrangeira e que o profissional tem conhecimento em informática, sendo a remuneração da profissão satisfatória. Além disso demonstrou que os profissionais da contabilidade buscam qualificação em cursos de educação continuada, dentro de sua área de atuação.

Aos contadores que seguirem esta carreira, observa-se que há mercado de trabalho, no entanto é necessário identificar-se com a profissão e ter uma afinidade com a área pública e interesse pela contabilidade governamental, assim sentir-se satisfeito e completado profissionalmente com sua função, além de ter estabilidade profissional. Além disso, o contador público levando em consideração a transparência dos resultados com a comunidade e municípios, agindo de forma ética, continuará sendo sempre um dos alicerces dos órgãos municipais dando saúde e continuidade as contas públicas dos municípios.

Como proposta para futuros estudos sugere-se aplicar o questionário para uma amostra com abrangência em todo o Estado do Rio Grande do Sul, a fim de conseguir identificar os perfis dos profissionais contábeis públicos, face a mudanças culturais existentes nas diversas regiões do estado. 


\section{REFERÊNCIAS}

AMERICAN INSTITUTE OF CERTIED PUBLIC ACCOUNTANTS - AICPA. Core competency framework for entry into the accounting profession. 2001. Disponível em $<$ www.aicpa.org/edu/func.htm $>$. Acesso em 04 de junho de 2015.

AZEVEDO, Ricardo Rocha. Uma Análise dos Índices da Lei De Responsabilidade Fiscal nos Municípios Paulistas após a Implantação do Projeto AUDESP. Revista de Gestão, Finanças e Contabilidade, ISSN 22385320, Salvador, v. 3, n. 2, p. 39-60, maio/ago., 2013.

AZEVEDO, Renato Ferreira Leitão. A Percepção pública dos contadores: "bem ou mal na foto"? São Paulo, 2010.

BEUREN, Ilse Maria (Org.),Como elaborar trabalhos monográficos em contabilidade: Teoria e Práticaz. Ed. São Paulo: Atlas, 2006.

BRASIL. Lei no 4.320 de 17 de março de 1964. Disponível em <http://www.stn.fazenda.gov.br/legislacao/download/ contabilidade/Lei4320.htm> Acesso em 11 de maio de 2015..

CALMON, Kátya Maria Nasiaseni; GUSSO, Divonzir Arthur. A Experiência de Avaliação do Plano Plurianual (Ppa) do Governo Federal No Brasil. 2002. Disponível em <http://ipea.gov.br/ppp/index.php/PPP/article/ viewFile/61/71> Acesso em 31 de maio de 2015.

CARVALHO, Deusvaldo. Orçamento e contabilidade pública. São Paulo: Elsevier, 2007 CARVALHO, Luis Nelson Guedes de; COSTA, Patricia de Souza; OLIVEIRA, Alan Teixeira. Impairment no setor público: particularidades das normas nacionais e internacionais. Revista de Administração Pública. Rio de Janeiro. v. 44. n.4. p. 839-876. jul./ago. 2010.

Conselho Federal de Contabilidade. Pesquisa Perfil do Profissional da Contabilidade 2012/13. Brasília. 2013. Disponível em < http://portalcfc.org.br/wordpress/ wpcontent/uploads/2013/12/livro_perfil_2013_ web2.pdf $>$ Acesso em 15 de maio de 2015.

Conselho Regional de Contabilidade do Rio Grande do Sul. NBCASP - Normas Brasileiras de Contabilidade Aplicada ao Setor Público sob a ótica da IPSAS: um estudo comparativo. $2^{\underline{a}}$ edição. Porto Alegre. 2014.

FLICK, U. Desenho da pesquisa qualitativa.

Porto Alegre: Artmed, 2009. 
Uma introdução à pesquisa qualitativa.

2.ed. Porto Alegre: Bookman, 2004.

GIL, Antonio Carlos. Métodos e técnicas de

pesquisa social. $4^{\underline{a}}$. ed. São Paulo: Altas, 2006.

Antonio Carlos. Como elaborar projetos

de pesquisa. 4. ed. São Paulo: Atlas, 2008.

Como Elaborar Projetos de

Pesquisa. São Paulo: Atlas, 2010.

GLAUBER, Francisco. Noções de Contabilidade Pública. 2003.

Disponível em <https://www.grancursos.com.br/downloads/

editora/adendos/contPub_70o.pdf $>$ Acesso em 11 de maio de 2015.

GONTIJO, Vander. Instrumentos de Planejamento e

Orçamentos. 2004. Disponível em <http://www2.camara.

leg.br/atividadelegislativa/orcamentobrasil/cidadao/entenda/

cursopo/pl anejamento.html> Acesso em 31 de maio de 2015.

IUDÍCIBUS, Sergio de. Teoria da Contabilidade.

10. ed. São Paulo: Atlas, 2010.

. Teoria da Contabilidade. 7.ed. São Paulo: Atlas, 2004.

. Contabilidade Gerencial. 4. ed. São Paulo: Atlas,1994.

IUDÍCIBUS, Sérgio de; MARION, José Carlos.

Introdução à Teoria da Contabilidade. Para o Nível de Graduação. 4.ed. São Paulo: Atlas, 2007.

IUDÍCIBUS, Sérgio de; MARION, José Carlos; FARIA, Ana Cristina de. Introdução à teoria da contabilidade: para o nível de graduação. 5.ed. São Paulo: Atlas, 2009.

JUNIOR, J. C. de M.; MEIRELLES, C. D. do A. A busca pela harmonização das normas internacionais de contabilidade. Revista Mineira de Contabilidade, Belo Horizonte, n. 33, p. 6-15, janeiro/fevereiro/março 2009.

KOHAMA, Helio. Contabilidade pública:

teoria e pratica. São Paulo: Atlas, 2003.

KOUNROUZAN, Marcia Covaciuc. O perfil do profissional contábil. 2002. Disponível em <http://www.oswaldocruz.br/ download/artigos/social17.pdf> Acesso em 20 de maio de 2015.

LAKATOS, Eva Maria; MARCONI, Marina de Andrade.

Metodologia do trabalho científico: procedimentos básicos, pesquisa bibliográfica, projeto e relatório, publicações e trabalhos científicos. 7. ed. São Paulo: Atlas, 2009. 
LIMA, Diana Vaz de; CASTRO Róbison Gonçalves de.

Contabilidade pública: integrando união, estados e municípios (siafi e siafem). São Paulo: Atlas, 2000.

LIMA, Diana Vaz de; CASTRO, Róbison

Gonçalves de. Contabilidade pública -

Integrando União, Estados e Municípios (Siafi

e Siafem). 2. ed. São Paulo : Atlas, 2003.

LIMA, Diana Vaz de; CASTRO Róbison Gonçalves de.

Contabilidade Pública. São Paulo: Atlas, 2007.

LIMA, Diana Vaz de; CASTRO Róbison Gonçalves de.

Contabilidade pública: integrando união, estados e

municípios (siafi e siafem). $3^{\text {a }}$ ed.São Paulo: Atlas, 2012.

LUNELLI, Reinaldo Luiz. A elaboração do Orçamento Público. 2002. Disponível em http://www.portaldecontabilidade.com.br/ tematicas/orcamentopublico.htm. Acesso em 31 de maio de 2015.

MARION, José Carlos. O Ensino da Contabilidade.

2. ed. São Paulo: Atlas, 2001.

MARION, José Carlos. Uma visão panorâmica da profissão contábil. Jornal do CRC. mar./abr 1999.

MARTINS, Gilberto de Andrade; LINTZ, Alexandre. Guia para elaboração de monografias e trabalhos de conclusão de curso. 2.ed. São Paulo: Atlas, 2007.

MEDEIROS, João Bosco. Redação científica: a prática de fichamentos, resumos, resenhas. 11. ed. São Paulo: Atlas, 2013.

MELLO, José Carlos Garcia de; Contabilidade

Pública. 2008. Disponível em <http://www.unifra.br/ pos/gestaopublica/downloads/CONTAB_PUBLIC. PDF> Acesso em 20 de maio de 2015.

NASCIMENTO, Edson Ronaldo; DEBUS, Ilvo. Lei Complementar 101/2000: Entendendo a Lei de Responsabilidade Fiscal. 1998. Disponível em $<$ http://www.fazenda.gov.br/arquivos-economiaservicos/entendendo-a-lei-de-responsabilida- defiscal>. Acesso em 31 de maio de 2015.

OLIVEIRA, João Paulo Sassioto Farias de. Tipos de Contabilidade. Disponível em: <https://www. portaleducacao.com.br/educacao/artigos/14428/tiposde-contabilidade> Acesso em o4 de maio de 2015. 
OLIVEIRA, Mariana Vieira de. O contador e suas conquistas profissionais: estudo comparativo dos recémformados da Univali e Unisul. 2008. Disponível em <http://tcc.bu.ufsc.br/Contabeis294324> Acesso em 25 de maio de 2015.

PARADA, Américo Garcia. Áreas de Atuação do profissional de Contabilidade. 2014. Disponível em < http://www.cosif. com.br/mostra.asp?arquivo=especializ2\#contadpublic $>$ Acesso em 28 de maio de 2015.

PIRES, Marco Antônio Amaral; MARQUES, Vagner Antônio. Elementos estruturais da teoria das funções sistemáticas. Revista Contabilidade e Informação, Ijuí, ano 10, n. 27, p.313. Jul./dez. 2007.

REIS, Heraldo da Costa. Impactos da LRF sobre a lei $\mathbf{n}$. 4.320. 2001. Disponível em https://web.bndes.gov.br/bib/ jspui/bitstream/1408/3481/1/Impactos\%20da\%20LRF\%20 sobre \%20a\%2oLei\%2on\%c2\%ba\%204320_Cadernos\%20 IBAM_2_P.pdf. Acesso em 31 de maio de 2015.

SÁ, Antonio Lopes de. Luca Pacioli: Um mestre do renascimento. Fundação Brasileira de Conatabilidade. Brasília. 2 ${ }^{\underline{a}}$ ed. 196p. 2004.

SACRAMENTO, Ana Rita Silva. Contribuições da Lei de Responsabilidade Fiscal para o avanço da Accountability no Brasil. Cadernos Gestão Pública e Cidadania/CEAPG. São Paulo, v. 10, n. 47, p. 20-47. Jul./Dez. 2005.

SCHMIDT, Paulo; SANTOS, José Luiz dos. História do pensamento contábil. São Paulo: Atlas, 2006.

SCHMIDT, Paulo; SANTOS, José Luiz dos. História do pensamento contábil. 1. ed. São Paulo 2008.

SILVA, Antônio Carlos Ribeiro da. Metodologia da pesquisa aplicada à contabilidade: Orientações de estudos, projetos, relatórios, monografias, dissertações, teses. São Paulo: Atlas, 2003.

SILVA, Bruno Adrian Carneiro da; CARRARA, Elenice de Oliveira; ALVES, Fabio da Cruz;

SILVA; Irene Caires da; PINTO, Marcelo Lanutte; MORAES, Maristela Regina. Profissão Contábil: Estudo das Características e sua Evolução no Brasil. 2011. Disponível em <http:// www.google.com.br> Acesso em 25 de maio de 2015. 
SILVA, Cristina de Jesus Martins da. CUSTOS

NO SETOR PÚBLICO: Análise dos artigos sobre

o tema Custos no Setor Público apresentados no

Congresso Brasileiro de Custos. Disponível em:

$<$ http://dspace.c3sl.ufpr.br/dspace/bitstream/

handle/1884/33849/CRISTINA\%20DE\%20JESU S\%20

MARTINS $\%$ 2oSILVA.pdf?sequence $=1 \&$ isAllowed $=\mathrm{y}>$

Acesso em 24 de maio de 2015.

SILVA, Lázaro Rosa da; BRITO, Valmir Bezerra de. O Novo

Código Civil para Contadores. 2. ed. São Paulo: IOB, 2003.

SILVA, Lino Martins. Contabilidade pública passa

por evolução. Revista brasileira de contabilidade.

São Paulo, ano 37, n. 173, p. 14. Set/Out. 2008.

SLOMSKI Valmor. Manual de contabilidade pública: um

enfoque na contabilidade municipal. 2. ed. São Paulo: Atlas, 2003.

SOUZA, Maria Lúcia Melo Deitos. Formação do profissional de ciências contábeis num contexto de permanente inovação nos processos produtivos. Revista Brasileira de Contabilidade, Brasília, v.37, n.170, p.78-91, Abr. 2008.

VIGNOLI, Francisco Humberto (coordenador); MORAES, Adelaide M. Bezerra et alli. A Lei de Responsabilidade Fiscal comentada para municípios. São Paulo. FGV / EAESP. 2002.

ZIVIANI, Juliardi. Lei de Responsabilidade Fiscal: planejamento, controle, transparência e responsabilização. 2004. Disponível em < http://jus.com.br/artigos/6026/leideresponsabilidade-fiscal> Acesso em 31 de maio de 2015. 